\title{
Resiliency to Amplification of Carbon Tetrachloride Hepatotoxicity by Chlordecone during Postnatal Development in Rats
}

\author{
ZHENGWEI CAI ${ }^{1}$ AND HARIHARA M. MEHENDALE \\ Division of Pharmacology and Toxicology, College of Pharmacy and Health Sciences, Northeast Louisiana \\ University, Monroe, Louisiana $71209-0470$
}

\begin{abstract}
The interactive hepatotoxicity of $\mathrm{CCl}_{4}$ and chlordecone, at an individually nontoxic dosage, was studied in neonatal and young developing rats. The well-documented amplification of $\mathrm{CCl}_{4}(100 \mu \mathrm{L} / \mathrm{kg})$ hepatotoxicity and lethality by prior dietary exposure to chlordecone $(10$ $\mathrm{ppm}$, for $15 \mathrm{~d}$ ) was absent in neonatal and developing rats through $35 \mathrm{~d}$ of age. The chlordecone-potentiated hepatotoxicity and lethality of $\mathrm{CCl}_{4}$ was partially expressed in 45-d-old rats and fully expressed in 60-d-old rats. Although hepatic microsomal cytochrome $\mathbf{P}-\mathbf{4 5 0}$ content in 2- or 5d-old rats was significantly lower than that in older age groups, the cytochrome P-450 content was not significantly different between 35-, 45-, and 60-d-old chlordeconetreated rats. During postnatal development, the ongoing hepatocellular proliferation declined in a biphasic manner, more rapidly up to $20 \mathrm{~d}$ and slowly thereafter, as indicated by ${ }^{3} \mathrm{H}$-thymidine incorporation in hepatic nuclear DNA. This pattern of postnatal liver proliferation and growth was not altered by exposure to chlordecone. In vivo metabolism of $\mathrm{CCl}_{4}$, in terms of ${ }^{14} \mathrm{CO}_{2}$ production derived from ${ }^{14} \mathrm{CCl}_{4}$ and ${ }^{14} \mathrm{CCl}_{4}$ metabolites bound to hepatic tissue, was not significantly different between 35-, 45-, and 60-d-old chlordecone-treated rats, whereas $\mathrm{CCl}_{4}$-stimulated hepatocellular regeneration in 35-d-old chlordecone-treated rats was significantly higher than in 45- or 60-d-old chlordecone-treated rats, as indicated by ${ }^{3} \mathrm{H}$-thymidine incorporation into hepatic DNA and histomorphometric analysis. These data suggest that the absence of potentiation of $\mathrm{CCl}_{4}$ toxicity by chlordecone in postnatally developing rats is well correlated with the presence of ongoing and stimulatable hepatocellular regenerative activity. (Pediatr Res 33: 225-232, 1993)
\end{abstract}

Abbreviations

CD, chlordecone

PB, phenobarbital

${ }^{3} \mathrm{H}$-T, ${ }^{3} \mathrm{H}$-thymidine

ALT, alanine transaminase

ND, normal diet

TGF, transforming growth factor

The remarkable potentiation of $\mathrm{CCl}_{4}$ hepatotoxicity by prior exposure to nontoxic levels of CD (10 ppm in diet for $15 \mathrm{~d})$ is well documented in male and female adult rats, as indicated by greatly increased hepatotoxicity and lethality of $\mathrm{CCl}_{4}$ at ordinarily

Received June 22, 1992; accepted November 4, 1992.

Correspondence and reprints requests: Dr. Harihara M. Mehendale, Division of Pharmacology and Toxicology, College of Pharmacy and Health Sciences, Northeast Louisiana University, Monroe, LA 71209-0470.

Supported jointly by grants from the Department of the Air Force, AFOSR-880009, and The Burroughs Wellcome Fund.

'Current address: Division of Newborn Medicine, Department of Pediatrics, University of Mississippi Medical Center, Jackson, MS 39216. nontoxic doses in CD-treated rats (1-3). A number of candidate mechanisms for this interaction have been considered (4). Increased bioactivation of $\mathrm{CCl}_{4}$ followed by increased lipid peroxidation is the foremost of these mechanisms in view of their wide acceptance with respect to $\mathrm{PB}$, alcohol, ketone, and other xenobiotic-induced enhancement of $\mathrm{CCl}_{4}$ toxicity (5-7). Studies of in vitro (8) and in vivo (9) metabolism of $\mathrm{CCl}_{4}$ in rats indicated that, although enhanced metabolism of $\mathrm{CCl}_{4}$ induced by cytochrome P-450 inducers such as $\mathrm{PB}$ and $\mathrm{CD}$ resulted in increased hepatotoxic effects of $\mathrm{CCl}_{4}$ initially, the alterations in $\mathrm{CCl}_{4}$ metabolism in PB- and CD-pretreated rats were not paralleled by the increase of $\mathrm{CCl}_{4}$ lethal effects. These studies revealed that a 3 -fold increase in $\mathrm{CCl}_{4}$ metabolism with a statistically nonsignificant 1.7 -fold increase in $\mathrm{CCl}_{4}$ lethality for $\mathrm{PB}$ rats was contrasted with a 2 -fold increase in $\mathrm{CCl}_{4}$ metabolism with 67 -fold increase in $\mathrm{CCl}_{4}$ lethality for $\mathrm{CD}$-treated rats. Therefore, enhanced metabolism of $\mathrm{CCl}_{4}$ did not adequately explain the mechanism of $\mathrm{CD}$-potentiated $\mathrm{CCl}_{4}$ hepatotoxicity. Other possible mechanisms including increased lipid peroxidation and covalent binding of $\mathrm{CCl}_{4}$ metabolites and the estrogenic property of $\mathrm{CD}$ have also been demonstrated not to be adequate explanations for the specificity and magnitude of CD-induced potentiation of $\mathrm{CCl}_{4}$ hepatotoxicity and lethality $(10,11)$.

On the other hand, evidence from histomorphometric studies $(12,13)$ and from subsequent investigations using ${ }^{3} \mathrm{H}-\mathrm{T}$ pulselabeling and autoradiography techniques and the partially hepatectomized animal model (14-17) are supportive of a novel hypothesis (4) that normally hepatocellular regeneration and repair of the hepatolobular architecture enable the animals to overcome and recover from injury initiated by a low dose of $\mathrm{CCl}_{4}$. These studies (14-17) also revealed that suppression of hepatocellular regeneration and tissue repair are responsible for the amplified hepatotoxicity of the same low dose of $\mathrm{CCl}_{4}$ by prior exposure to $\mathrm{CD}$. The suppressed $\mathrm{CCl}_{4}$-stimulated hepatocellular regeneration and tissue repair in $C D$-treated rats has been shown to be due to a precipitous depletion in hepatocellular ATP (18). Significant attenuation of $\mathrm{CD}$-amplified $\mathrm{CCl}_{4}$ hepatotoxicity afforded by administration of (+)-cyanidanol, which significantly restored cellular regeneration and tissue repair as a consequence of increased hepatic ATP levels $(19,20)$, provided further supportive evidence for the hypothesis.

Although most hepatocytes in adult rats are in a nonproliferating quiescent state, during postnatal development hepatocytes actively proliferate and liver growth occurs. In the present study, we used newborn and young animals as an additional model to test the role of active cell division in resistance to potentiated hepatotoxicity of $\mathrm{CCl}_{4}$ by $\mathrm{CD}$.

During postnatal development, the newborn and young animals are usually more sensitive than adults to many drugs and toxicants $(21-26)$. However, the newborns are less sensitive to chemicals like $\mathrm{CCl}_{4}$ whose toxicity is dependent on prior metabolic activation to the toxic species $(7,27,28)$, because they have 
a less than fully developed cytochrome $\mathrm{P}-450$ system. To consider the differences in $\mathrm{CCl}_{4}$ bioactivation, which might result in the differences in resiliency to the potentiation of $\mathrm{CCl}_{4}$ hepatotoxicity by $\mathrm{CD}$, in vivo metabolism of $\mathrm{CCl}_{4}$ was also investigated in rats at various ages with or without the $\mathrm{CD}$ pretreatment.

\section{MATERIALS AND METHODS}

Chemicals. Unless otherwise stated, all chemicals and enzyme kits used in this study were purchased from Sigma Chemical Co. (St. Louis, MO). ${ }^{3} \mathrm{H}-\mathrm{T}$ (sp act $20 \mathrm{Ci} / \mathrm{mmol}$ ) and ${ }^{14} \mathrm{CCl}_{4}(99 \%$ purity, $2.8 \mathrm{mCi} / \mathrm{mmol}$ ) were obtained from New England $\mathrm{Nu}-$ clear (Boston, MA). ${ }^{14} \mathrm{CCl}_{4}$ was prepared with unlabeled $\mathrm{CCl}_{4}$ in corn oil to achieve a concentration of $\mathrm{CCl}_{4}(100 \mu \mathrm{L} / \mathrm{mL})$ with a sp act of $0.013 \mathrm{mCi} / \mathrm{mmol}$. Analytical grade $\mathrm{CCl}_{4}$ and scintillation fluid, Scintiverse E SX 16-4, were purchased from Fisher Scientific Company (Baton Rouge, LA). For lethality and hepatotoxicity studies, $\mathrm{CCl}_{4}$ was dissolved in corn oil at concentrations of either 50 or $100 \mu \mathrm{L} / \mathrm{mL}$ for intraperitoneal administration.

Animals. Male Sprague-Dawley rats at the age of 20,30 , or 45 $\mathrm{d}$ and pregnant female rats at $\mathrm{d} 7$ of gestation were purchased from Charles River Breeding Laboratories (Wilmington, MA) and maintained in our central animal facilities away from any contaminants. All experiments were performed humanely and with the approval of the Institutional Animal Care and Use Committee.

The male rats were housed four per cage and pregnant female rats two per cage over untreated corn cob bedding under a 12-h photoperiod, $50-80 \%$ humidity, at $21^{\circ} \mathrm{C}$. Water and powdered Purina rodent chow (diet no. 5001, Purina Chow Co., St. Louis, $\mathrm{MO}$ ) containing $10 \mathrm{ppm} \mathrm{CD}$ were provided ad libitum to male rats at the age of 20,30 , or $45 \mathrm{~d}$ for $15 \mathrm{~d}$. This diet was prepared as previously described by Curtis and Mehendale (29). On d 16 of the dietary protocol (when the rats reach 35,45 , and $60 \mathrm{~d}$ of age, respectively), they were used for lethality, ${ }^{14} \mathrm{CCl}_{4}$ metabolism, ${ }^{3} \mathrm{H}-\mathrm{T}$ incorporation, or other studies. Pregnant female rats were provided with a similarly prepared CD diet $(30 \mathrm{ppm})$ for $15 \mathrm{~d}$, starting from 7 or $10 \mathrm{~d}$ of gestation or $5 \mathrm{~d}$ postparturition such that their 2-, 5-, and 20-d-old offspring would have been also exposed to $\mathrm{CD}$ for $15 \mathrm{~d}$, either transplacentally or through milk feeding. On d 18 of gestation, the pregnant rats were separated from each other and maintained in individual cages. On d 16 of the dietary protocol, the 2-, 5-, and 20-d-old rats were used for lethality, ${ }^{3} \mathrm{H}-\mathrm{T}$ incorporation, and hepatic CD deposition measurements (in some studies, the 5-d-old group was omitted). Control rats were maintained on a similarly prepared powdered diet without the addition of CD. Only male rats were used for experimental measurement, except for the 2-d-old group, in which blood or hepatic tissue samples from two to three pups had to be pooled for a single measurement. Because no significant difference in the parameters measured was found between males and females in that group, data for males and females were pooled to reduce the number of pups needed.

Lethality. Lethality induced by a single dose of $\mathrm{CCl}_{4}(100 \mu \mathrm{L} /$ $\mathrm{kg}$ ) was determined in 2-, 20-, 35-, 45-, and 60-d-old rats with or without $C D$ pretreatment. After the rats were challenged with an intraperitoneal injection of $\mathrm{CCl}_{4}$, they were observed for $14 \mathrm{~d}$ and lethality was recorded. Carbon tetrachloride was prepared in corn oil in a concentration of $50 \mu \mathrm{L} / \mathrm{mL}$ for 2 - and 20 -d-old rats and $100 \mu \mathrm{L} / \mathrm{mL}$ for rats in other age groups.

Microsomal cytochrome P-450. Hepatic microsomal protein and cytochrome P-450 content in 2-, 5-, 20-, 35-, 45-, and 60-dold rats with or without $C D$ pretreatment were determined using the methods of Lowry (30) and Omura and Sato (31), respectively.

Evaluation of $\mathrm{CCl}_{4}$ hepatotoxicity. Rats were killed under diethyl ether anesthesia, and hepatotoxicity was assessed at a series of time points after the challenge with a single intraperitoneal dose of $\mathrm{CCl}_{4}(100 \mu \mathrm{L} / \mathrm{kg})$ by assessing elevation of serum ALT (EC 2.6.1.2.) following the method of Reitman and Frankel
(32) and by histopathologic examination of the liver tissue for cellular necrosis. Volume density of hepatocytes with each of the various morphologic features was separately determined according to Weibel et al. (33). Control groups were injected with corn oil.

Estimation of $C D$ deposition in hepatic tissue. To validate our $\mathrm{CD}$ pretreatment of the infants through dietary exposure to the dams, the CD concentrations in newborn and young rat hepatic tissue were measured by gas chromatography as described by Curtis and Mehendale (34).

${ }^{3} H$-T incorporation into liver nuclear DNA. Together with the evidence from mitotic activity, ${ }^{3} \mathrm{H}-\mathrm{T}$ incorporation into liver nuclear DNA was measured as an index of hepatocellular regenerative activity, following the procedures described previously (35). ${ }^{3} \mathrm{H}-\mathrm{T}$ was administered at a dose of $200 \mu \mathrm{Ci} / \mathrm{kg} 2 \mathrm{~h}$ before the animals were killed. The procedure used for isolation of liver nuclear DNA was that described by Chang and Looney (36). The DNA content was measured with the diphenylamine reaction as described by Burton (37). ${ }^{3} \mathrm{H}-\mathrm{T}$ incorporation data were expressed as $\mathrm{cpm} / \mathrm{mg}$ DNA.

In vivo metabolism of ${ }^{14} \mathrm{CCl}_{4}$. The procedure for estimation of in vivo metabolism of ${ }^{14} \mathrm{CCl}_{4}$ in $35-, 45$-, and 60 -d-old rats with or without $\mathrm{CD}$ pretreatment was the same as that described earlier $(9,38)$. Briefly, after injection of ${ }^{14} \mathrm{CCl}_{4}$ at a dose of 100 $\mu \mathrm{L} / \mathrm{kg}$, the rat was put in a glass metabolic chamber. The expired air was successively drawn at an approximate flow rate of 800 $\mathrm{mL} / \mathrm{min}$ through two traps containing $10 \mathrm{~mL}$ of toluene to collect unmetabolized ${ }^{14} \mathrm{CCl}_{4}$ and a third trap containing $10 \mathrm{~mL}$ of $\mathrm{NaOH}$ to collect ${ }^{14} \mathrm{CO}_{2}$ derived from ${ }^{14} \mathrm{CCl}_{4}$. Each of the traps was immersed in an ice water bath maintained at $4^{\circ} \mathrm{C}$. Trap contents were removed for analysis at hourly intervals for $6 \mathrm{~h}$. The radioactivity of collected ${ }^{14} \mathrm{CCl}_{4}$ and ${ }^{14} \mathrm{CO}_{2}$ was counted in a Packard 2200CA Tri-Carb Liquid Scintillation Analyzer (Packard Instrument Co., Meriden, CT) and expressed as dpm. Upon completion of the 6-h collection interval, the liver was surgically removed while the rat was under diethyl ether anesthesia for the estimation of ${ }^{14} \mathrm{CCl}_{4}$ metabolites bound to liver tissue.

Total hepatic ${ }^{14} \mathrm{C}$ and ${ }^{14} \mathrm{CCl}_{4}$ metabolites bound to hepatic tissue were determined as previously described (38) and expressed as $\mathrm{dpm} / \mathrm{g}$ liver.

Statistics. Data of measured variables from various age groups at the corresponding time points were subjected to conventional one-way analysis of variance. Duncan's multiple comparison was used to determine the significance of differences between groups when one-way analysis of variance indicated a significant $F$ value. The $\chi^{2}$ test was used to determine the significance of the difference in mortality between groups. The level of statistical significance was set at $p \leq 0.05$.

\section{RESULTS}

Lethality. The mortality induced by a single dose of $\mathrm{CCl}_{4}(100$ $\mu \mathrm{L} / \mathrm{kg}$ ) in 2-, 20-, 35-, 45-, and 60-d-old rats with or without CD pretreatment during $14 \mathrm{~d}$ is shown in Table 1 . No mortality was observed in control rats at any age and in CD-treated rats at the age of 2, 20, and $35 \mathrm{~d}$. Mortality first appeared in the 45-d-old group treated with $\mathrm{CD}$ and was further significantly increased in 60-d-old CD-treated rats, indicating that the toxicity of a nontoxic dose of $\mathrm{CCl}_{4}$ was greatly amplified by $\mathrm{CD}$ only in certain age groups. Animal death occurred only during 36 to $72 \mathrm{~h}$ after the $\mathrm{CCl}_{4}$ administration.

$C D$ Deposition in Hepatic Tissue. Hepatic concentrations of $\mathrm{CD}$ in newborn and young rats exposed to a $\mathrm{CD}$ diet for $15 \mathrm{~d}$ are listed in Table 2. These values are comparable to the hepatic $\mathrm{CD}$ concentration in adult rats pretreated with $10 \mathrm{ppm}$ dietary $\mathrm{CD}, 51.6 \pm 0.9 \mu \mathrm{g} / \mathrm{g}$ liver, which resulted in remarkable potentiation of hepatotoxic and lethal effects of an ordinarily nontoxic dose of $\mathrm{CCl}_{4}$ (34). These values also suggest that our dietary pretreatment of the newborn or young rats via dietary exposure of the mother rats is effective and that the lack of CD-potentiated 
Table 1. Lethality within $14 \mathrm{~d}$ after $\mathrm{CCl}_{4}$ administration in rats at different ages*

\begin{tabular}{ccc}
\hline Age (d) & $\begin{array}{c}\text { ND } \\
(n=10) \dagger\end{array}$ & $\begin{array}{c}\text { CD diet } \\
(10 \mathrm{ppm})\end{array}$ \\
\hline 2 & 0 & $0(10) \dagger$ \\
20 & 0 & $0(10)$ \\
35 & 0 & $0(32)$ \\
45 & 0 & $24 \% \dagger(25)$ \\
60 & 0 & $90 \% \S(10)$ \\
\hline
\end{tabular}

* After the CD preexposure regimen, the rats were injected intraperitoneally with a single dose of $100 \mu \mathrm{L} \mathrm{CCl} / \mathrm{kg}$ body weight in corn oil vehicle.

$\dagger$ The numbers in parentheses are total number of animals treated.

$\ddagger p<0.05$ compared with 0 .

$\S p<0.01$ compared with 0 .

lethal effects of $\mathrm{CCl}_{4}$ in 2- and 20-d-old rats is unlikely to be due to insufficient deposition of CD in hepatic tissue.

Hepatic Microsomal Cytochrome P-450. The hepatic microsomal cytochrome P-450 content increased with age (Fig. 1). At the ages of 2 and $5 \mathrm{~d}$, the cytochrome P-450 level was significantly lower than in the older groups. CD treatment seemed to accelerate the rate of increase in cytochrome P-450 with age. On $\mathrm{d}$ 20 , cytochrome P-450 in CD-treated rats reached the plateau level and it was significantly higher than in the control rats. By $35 \mathrm{~d}$ after birth, the cytochrome P-450 level started plateauing in both control and CD-treated rats. CD pretreatment is known to increase cytochrome P-450 content, and this increase was evident at all ages.

Hepatotoxicity of $\mathrm{CCl}_{4}$. Within $24 \mathrm{~h}$ after the injection of $\mathrm{CCl}_{4}$, the ALT level in 2-d-old rats was fairly stable regardless of the pretreatment, indicating a lack of hepatotoxicity (Fig. 2). The ALT level in 20 -d-old rats with or without CD pretreatment also remained stable after the administration of $\mathrm{CCl}_{4}$ (data not shown). In contrast to this, the combination of $\mathrm{CD}+\mathrm{CCl}_{4}$ resulted in significantly elevated ALT levels in 35-, 45-, and 60d-old rats as early as 2 or $6 \mathrm{~h}$ after the $\mathrm{CCl}_{4}$ administration, whereas the same dose of $\mathrm{CCl}_{4}$ had no effect on the ALT level in control diet-fed rats (Fig. $3 a$ and $b$ ). The elevated ALT levels were not significantly different among $35-, 45-$, and 60-d-old $\mathrm{CD}$-treated rats at the 2 and $6 \mathrm{~h}$ time points, indicating that the initial liver injury in these groups was very similar. By 24 and $48 \mathrm{~h}$ after $\mathrm{CCl}_{4}$ injection, the ALT levels in 45- and 60-d-old CD-treated rats were further dramatically elevated, whereas the ALT level in 35-d-old CD-treated rats did not increase much more (Fig. $3 c$ and $d$ ), suggesting that the progression of the initiated liver injury by $\mathrm{CCl}_{4}$ in 35 -d-old CD-treated rats was different from that in 45 - or 60 -d-old CD-treated rats. It should be noted that animal death occurs in these two groups after 36 $\mathrm{h}$, and the ALT values were measured only from the surviving rats. Therefore, the ALT level in 45- or 60-d-old CD-treated rats $48 \mathrm{~h}$ after the $\mathrm{CCl}_{4}$ administration may even be underestimated here.

${ }^{3} H$-T Incorporation into Liver Nuclear DNA. In the absence of $\mathrm{CCl}_{4}$ administration, the ${ }^{3} \mathrm{H}-\mathrm{T}$ incorporation rate decreased significantly with the increase of age regardless of the dietary treatment (Fig. 4). The 2- and 5-d-old rats had much higher ${ }^{3} \mathrm{H}$ $\mathrm{T}$ incorporation rates than other age groups and the incorporation rates at 20 or $35 \mathrm{~d}$ were still significantly higher than in the older groups (Fig. 4, insert). CD treatment had no significant effects on ${ }^{3} \mathrm{H}-\mathrm{T}$ incorporation for any of these age groups.
Because 35-, 45-, and 60-d-old CD-treated rats had similar initial liver injury $6 \mathrm{~h}$ after the administration of $\mathrm{CCl}_{4}$ but had a dramatically different final outcome of toxicity, we determined levels of ${ }^{3} \mathrm{H}-\mathrm{T}$ incorporation into hepatic nuclear DNA in these groups at 2,6,24, and $48 \mathrm{~h}$ after $\mathrm{CCl}_{4}$ as an index of tissue repair activity.

Two h after $\mathrm{CCl}_{4}$ administration, ${ }^{3} \mathrm{H}-\mathrm{T}$ incorporation was significantly increased in 45- and 60-d-old ND-fed rats, but not in CD-treated rats, as compared with the respective corn oilinjected control groups (Fig. 5a). The administration of $\mathrm{CCl}_{4}$ also resulted in an elevation of ${ }^{3} \mathrm{H}$ - $\mathrm{T}$ incorporation in 35-d-old ND-fed rats, but the increase was not statistically significant. This is probably due to the higher rate of ${ }^{3} \mathrm{H}-\mathrm{T}$ incorporation in 35 -d-old control rats in comparison to the older groups. The ${ }^{3} \mathrm{H}$ $\mathrm{T}$ incorporation level in 35-d-old ND-fed or CD-treated rats challenged with $\mathrm{CCl}_{4}$ was significantly higher than in the older ones receiving the same treatment (Fig. $5 a$ ), and this trend was also evident at $6 \mathrm{~h}$ after $\mathrm{CCl}_{4}$ administration (Fig. $5 b$ ). By $24 \mathrm{~h}$ after $\mathrm{CCl}_{4}$ injection, a significant increase in ${ }^{3} \mathrm{H}$-T was observed in 35- and 45-d-old rats but not in 60-d-old CD-treated rats as compared with the control or the corn oil-injected CD-treated rats (Fig. $5 c$ ). The increased ${ }^{3} \mathrm{H}$-T incorporation rate in 35 -d-old CD-treated rats was much higher than observed in older age groups challenged with the same dose of $\mathrm{CCl}_{4}$. The administration of $\mathrm{CCl}_{4}$ induced significant increases in ${ }^{3} \mathrm{H}$-T incorporation by $48 \mathrm{~h}$ in both ND-fed and CD-treated rats at all ages studied (Fig. $5 d$ ). However, because ${ }^{3} \mathrm{H}$-T incorporation in 60-d-old CDtreated rats was measured only in surviving individuals and most individuals of this group died by that time, the ${ }^{3} \mathrm{H}-\mathrm{T}$ incorporation rate in this group presented here is likely to be an overestimate.

Histomorphometric Measurements. Necrosis. The volume density of necrotic hepatocytes at various time points after $\mathrm{CCl}_{4}$ administration observed in 35-, 45-, and 60-d-old rats with different pretreatments is presented in Figure $6 a, b$, and $c$, respectively. Consistent with our serum enzyme data, no significant necrosis of hepatocytes was observed in the livers of rats injected with corn oil at any time point studied regardless of dietary treatment and age. Administration of $\mathrm{CCl}_{4}$ did not result in a significant increase in volume density of necrotic hepatocytes at $6 \mathrm{~h}$ in 35- and 45-d-old ND-fed or CD-treated rats. Volume density of necrotic hepatocytes in 60-d-old rats was slightly increased by $6 \mathrm{~h}$, but the increase was not significantly different between $\mathrm{ND}$-fed and $\mathrm{CD}$-treated rats $(3.6$ and $2.6 \%$, respectively). Necrosis of hepatocytes induced by $\mathrm{CCl}_{4}$ was slightly increased in ND rats of all the three age groups by $24 \mathrm{~h}$ and remained low or returned to the level before $\mathrm{CCl}_{4}$ challenge by $48 \mathrm{~h}$. In 45 - and 60 -d-old CD-treated rats, $\mathrm{CCl}_{4}$-induced hepatic necrosis was greatly increased by $24 \mathrm{~h}$ and the necrotic injury was further increased by $48 \mathrm{~h}$. In 35-d-old CD-treated rats, although $\mathrm{CCl}_{4}$-induced hepatic necrosis was significantly increased by $24 \mathrm{~h}$, there was no further increase at $48 \mathrm{~h}$.

Mitosis. The hepatic mitotic activity, as estimated by volume density of hepatocytes in metaphase (shown in Fig. 7a, b, and $c$ for 35-, 45-, and 60-d-old rats, respectively) in corn oil-injected groups remained fairly stable regardless of the dietary treatment and age. It should be noted that hepatic mitotic activity in 35-dold rats was generally higher, although not statistically significant at all the time points studied, in comparison with 45- and 60-dold rats regardless of the dietary treatment. There was a significant increase in hepatic mitotic activity in 45- and 60-d-old NDfed rats $24 \mathrm{~h}$ after $\mathrm{CCl}_{4}$ challenge (Fig. $7 b$ and $c$ ). The adminis-

Table 2. Hepatic disposition of CD in newborn and weaning rats after dietary treatment (30 ppm) of their dams

\begin{tabular}{cccc}
\hline CD concentration in dam's diet $(\mathrm{ppm})$ & Starting day of diet after successful mating & $\begin{array}{c}\text { Age of newborn } \\
\text { rats (d) }\end{array}$ & $\begin{array}{c}\text { Hepatic concentration } \\
\text { of CD ( } \mu \mathrm{g} / \mathrm{g} \text { liver })\end{array}$ \\
\hline 30 & 7 & 2 & $48.9 \pm 3.8$ \\
30 & 10 & 5 & $64.3 \pm 1.4$ \\
30 & 5 postparturition & 20 & $66.9 \pm 12.9$ \\
\hline
\end{tabular}




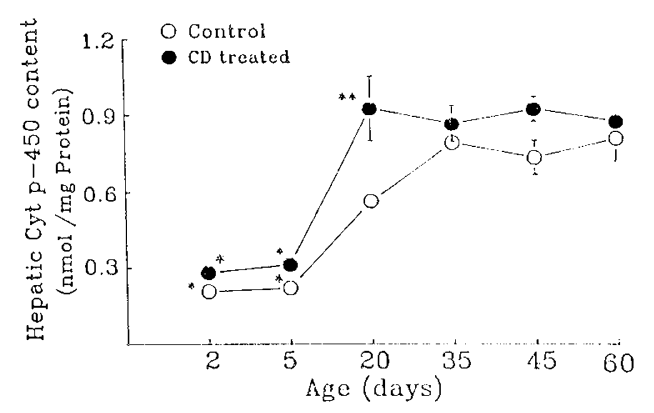

Fig. 1. Hepatic microsomal cytochrome P-450 (Cyt p-450) content in rats at various ages with or without dietary $C D$ pretreatment. Each point represents the mean \pm SEM of three to four measurements. Two or three livers were pooled for a single measurement in 2- or 5-d-old rats. One asterisk indicates a significant difference from 20-d-old and older rats with the same dietary treatment. Two asterisks indicate a significant difference between CD- and ND-fed rats of 20-d age group.

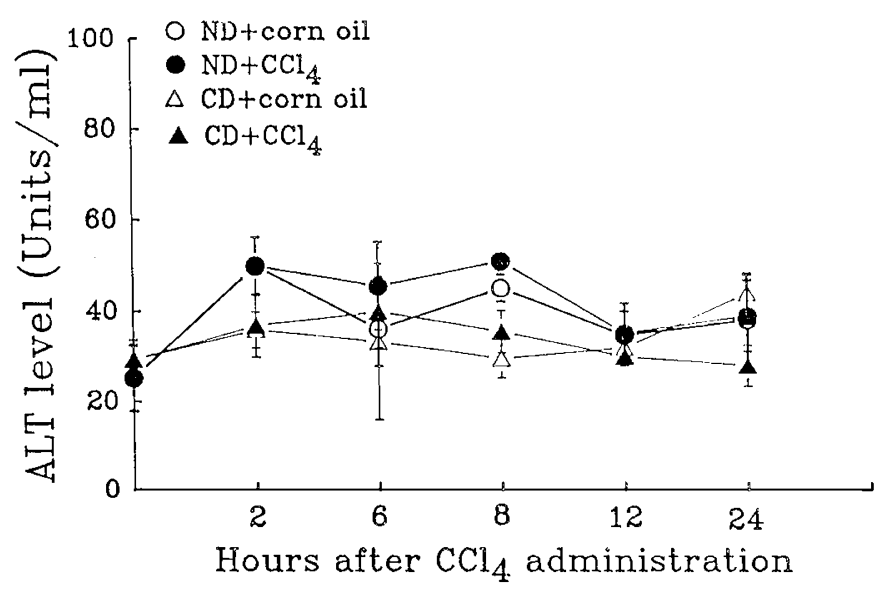

Fig. 2. Serum ALT levels over $24 \mathrm{~h}$ after the injection of $\mathrm{CCl}_{4}(100$ $\mu \mathrm{L} / \mathrm{kg}$ ) or corn oil in 2-d-old rats exposed to an ND or CD (30 ppm) diet through their dams for $15 \mathrm{~d}$. The results represent the means \pm SEM of at least four measurements. Serum from two or three pups was pooled for a single measurement.

tration of $\mathrm{CCl}_{4}$ also induced an increase in mitotic activity in 35d-old ND-fed rats, but it was not statistically significant due to the relatively high baseline level of mitotic activity in this age group. The difference in hepatic necrosis induced by $\mathrm{CCl}_{4}$ at 24 and 48 h between 35-, 45-, and 60-d-old CD-treated rats (Fig. $6 a-c)$ was commensurate with the difference in mitotic activity between these age groups. At $24 \mathrm{~h}$, there was a significant increase in hepatic mitotic activity in 35-d-old CD-treated rats (Fig. 7a), whereas hepatic mitotic activity in 45 - or 60 -d-old CD-treated rats was not stimulated during the $48 \mathrm{~h}$ after $\mathrm{CCl}_{4}$ administration (Fig. $7 b$ and $c$ ).

In Vivo Metabolism of ${ }^{14} \mathrm{CCl}_{4}$. The data on the in vivo metabolism of ${ }^{14} \mathrm{CCl}_{4}$ are summarized in Table 3 . Regardless of the age and dietary treatments, 80 to $85 \%$ of the administered ${ }^{14} \mathrm{CCl}_{4}$ was expired as unmetabolized parent compound within $6 \mathrm{~h}$. CD pretreatment resulted in a significant increase in the proportion of administered ${ }^{14} \mathrm{CCl}_{4}$ expired as ${ }^{14} \mathrm{CO}_{2}$ compared with the NDfed rats in the respective age groups, indicating an increased bioactivation of $\mathrm{CCl}_{4}$ in $\mathrm{CD}$-treated rats. Bioactivation of ${ }^{14} \mathrm{CCl}_{4}$ in 35-d-old CD-treated rats was significantly higher than in 45or 60-d-old rats as indicated by a greater portion of the administered ${ }^{14} \mathrm{CCl}_{4}$ expired as ${ }^{14} \mathrm{CO}_{2}$. The total hepatic radioactivity and the radioactivity bound to tissue in 35-d-old CD-treated rats were significantly lower than in 60 -d-old $C D$-treated rats but not significantly lower than in 45-d-old CD-treated rats.

\section{DISCUSSION}

Hepatotoxicity of $\mathrm{CCl}_{4}$ in different age groups has been investigated in several studies. Because $\mathrm{CCl}_{4}$ toxicity is dependent on prior hepatic activation, it was hypothesized in several studies that the newborn animals would be less sensitive to $\mathrm{CCl}_{4}$-induced hepatotoxicity $(39,40)$. Although 1 -d-old rats were found to be resistant to $\mathrm{CCl}_{4}$-induced hepatic damage (39), rats as young as $4 \mathrm{~d}$ of age had extensive hepatic damage after $\mathrm{CCl}_{4}$ treatment, and hepatic necrosis in 10-, 14-, and 21-d-old rats was of the same order of magnitude as observed in adults after $\mathrm{CCl}_{4}$ treatment (40). A relatively high dose of $\mathrm{CCl}_{4}(1$ or $2 \mathrm{~mL} / \mathrm{kg})$ was used in the above-mentioned studies. It has also been reported that aging had no effects on hepatotoxicity of $\mathrm{CCl}_{4}$ (41). The decreased metabolic activation of $\mathrm{CCl}_{4}$ in aged rats (5-mo-old versus 20 -mo-old rats) is counterbalanced by a diminished defense mechanism against peroxidative attack and the net result is no change in the extent of liver damage (41). In the present study, we found that newborn and developing rats are more resilient to hepatotoxicity of a low dose of $\mathrm{CCl}_{4}$ as well as to its potentiation by pretreatment with $\mathrm{CD}$.

Several possible mechanisms may contribute to the observed resilience to amplification of $\mathrm{CCl}_{4}$ hepatotoxicity by $\mathrm{CD}$ in postnatally developing rats. Because hepatic deposition of $\mathrm{CD}$ in 2 - and 20 -d-old rats after $15 \mathrm{~d}$ of dietary exposure is comparable to that of adult CD-pretreated rats (Table 2), insufficient accumulation of $C D$ in hepatic tissue could be excluded from the list of possible mechanisms for the lack of $\mathrm{CD}$-potentiated $\mathrm{CCl}_{4}$ toxicity. An important reason for the resilience to potentiation of $\mathrm{CCl}_{4}$ hepatotoxicity and lethality in newborn rats could be less metabolic bioactivation of $\mathrm{CCl}_{4}$. The level of hepatic microsomal cytochrome P-450, which is required for the initiation of $\mathrm{CCl}_{4}$-induced liver damage, was much lower in 2-d-old CDtreated rats than in older CD-treated rats (Fig. 1), and this might explain the absence of $\mathrm{CD}$-potentiated $\mathrm{CCl}_{4}$ toxicity in that group. However, the cytochrome P-450 levels in 35-, 45-, and 60-d-old CD-treated rats were not significantly different (Fig. 1). Some isoenzymes of cytochrome P-450 have been reported to be more effective than others in metabolizing $\mathrm{CCl}_{4}(42,43)$, and they may develop differently with age. To examine such a possibility, which may be responsible for the observed differences in resilience to amplification of $\mathrm{CCl}_{4}$ toxicity by $\mathrm{CD}$ among different age groups, in vivo metabolism of $\mathrm{CCl}_{4}$ was investigated. Data on the in vivo metabolism of $\mathrm{CCl}_{4}$ (Table 3) indicate that bioactivation of $\mathrm{CCl}_{4}$ was not significantly different among the $35-, 45-$, and 60-d-old CD-treated rats, whereas $\mathrm{CCl}_{4}$ toxicity showed significant differences among these groups (Table 1 and Fig. 3). These results suggest that neither cytochrome P-450 level nor metabolic activation of $\mathrm{CCl}_{4}$ could explain the absence of $\mathrm{CD}$-potentiated $\mathrm{CCl}_{4}$ hepatotoxicity and lethality in 35-d-old CD-treated rats.

It is apparent from the present study that the absence or presence of $\mathrm{CD}$-potentiated $\mathrm{CCl}_{4}$ hepatotoxicity and lethality is well correlated with the presence or absence of ongoing and stimulated hepatocellular regeneration and tissue repair. The serum enzyme and histomorphometric data (Figs. 3, 6, and 7) indicate that $\mathrm{CCl}_{4}$ at a dose of $100 \mu \mathrm{L} / \mathrm{kg}$ !did not result in significant liver damage in ND-fed rats regardless of age, whereas there was a stimulated or ongoing hepatic proliferative activity as early as $2 \mathrm{~h}$ in these groups as indicated by the ${ }^{3} \mathrm{H}-\mathrm{T}$ incorporation data (Fig. 5). No hepatocellular regenerative or tissue repair activity was observed until $48 \mathrm{~h}$ in 60 -d-old CD-rats (Fig. 5 ), in which remarkably potentiated $\mathrm{CCl}_{4}$ hepatotoxicity and lethality were observed (Table 1 and Fig. 3). In contrast to the observation in 60-d-old CD-treated rats, $C D$ treatment did not affect the ongoing hepatocellular proliferation in 35-d-old rats and a further increase of regenerative or tissue repair activity was noticeable at $24 \mathrm{~h}$ in that group, in which no lethality and much less toxicity of $\mathrm{CCl}_{4}$ were observed. Previous studies $(10,14,15)$ 


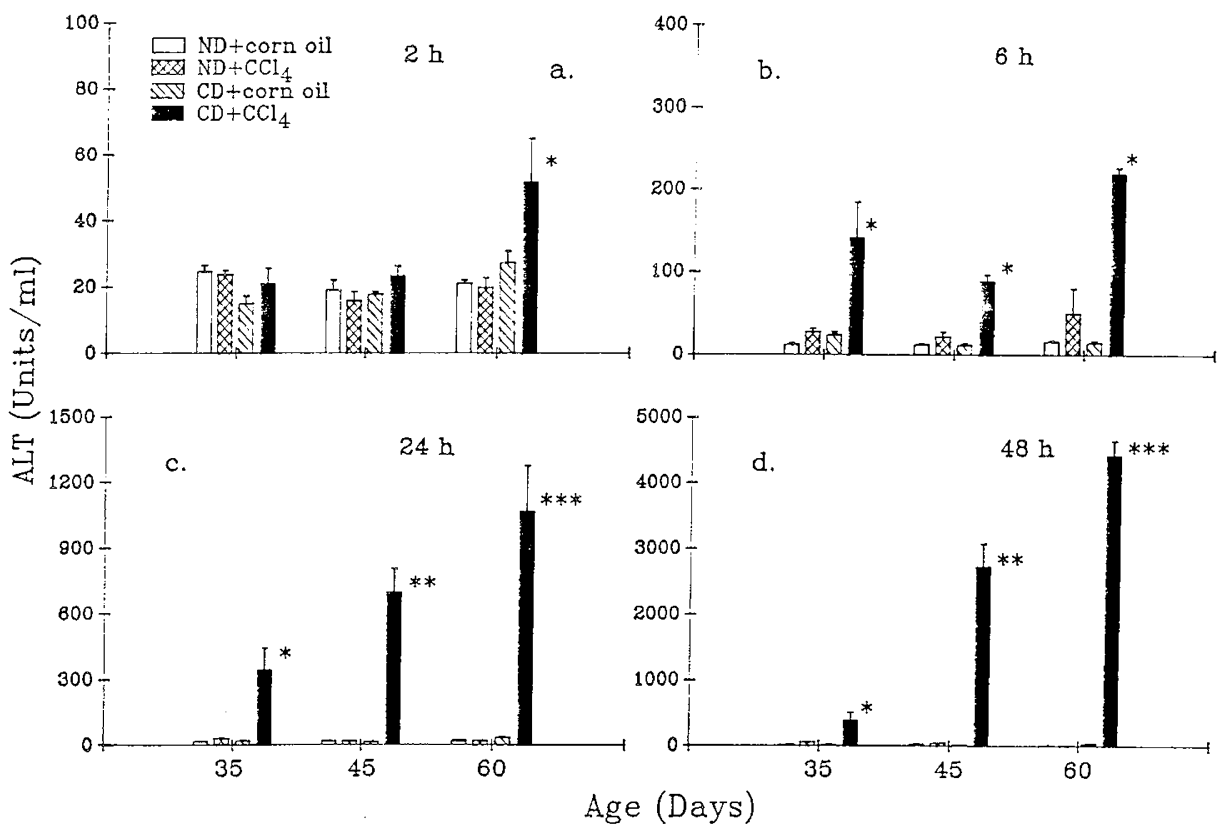

Fig. 3. Serum ALT levels at $2(a), 6(b), 24(c)$, and $48(d)$ h after the injection of $\mathrm{CCl}_{4}(100 \mu \mathrm{L} / \mathrm{kg})$ or corn oil in 35-, 45-, and 60 -d-old rats fed either an ND or CD $(10 \mathrm{ppm})$ diet. (Note the difference in scale for each of panels.) The results represent the means \pm SEM of at least four rats. A single asterisk indicates a significant increase in ALT level as compared with corn oil-injected ND-fed rats at the same age. Two asterisks indicate that the ALT level is significantly higher than in 35-d-old $\mathrm{CD}+\mathrm{CCl}_{4}$ rats. Three asterisks indicate a significantly higher ALT level as compared with that in 35 - or 45 -d-old $\mathrm{CD}+\mathrm{CCl}_{4}$ rats.

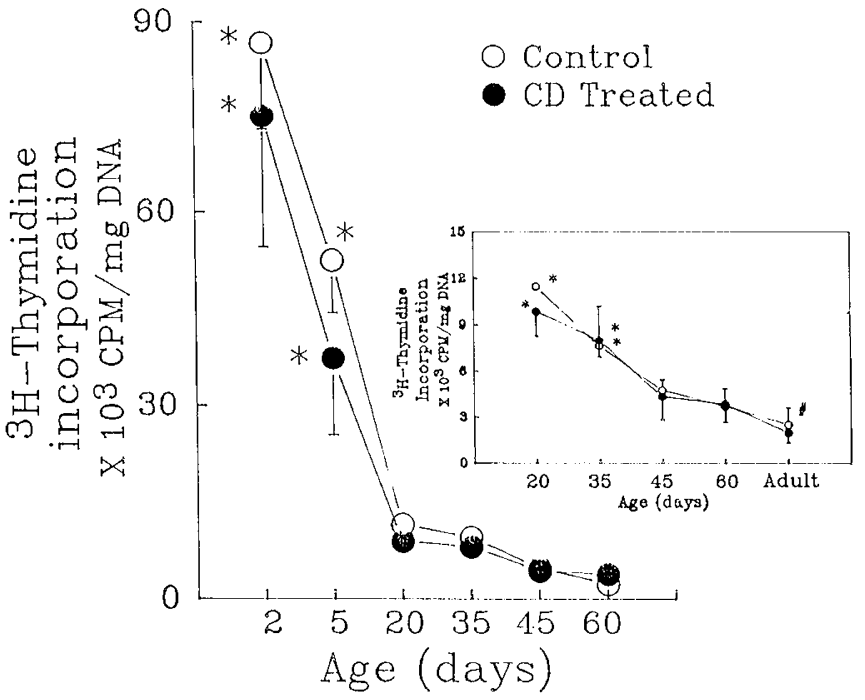

Fig. 4. ${ }^{3} \mathrm{H}-\mathrm{T}$ incorporation in the hepatic nuclear DNA of rats of different ages fed either an ND or CD diet. ${ }^{3} \mathrm{H}-\mathrm{T}$ was administered at a dose of $200 \mu \mathrm{Ci} / \mathrm{kg} 2 \mathrm{~h}$ before the animals were killed. Each point represents the mean $\pm \mathrm{SEM}$ of at least four rats. One asterisk indicates a significant difference from the rats older than $20 \mathrm{~d}$ with the same dietary treatment. The insert is a magnification of data for rats older than $20 \mathrm{~d}$. The adult data are cited from reference 15 with permission from the authors.

have also shown that $\mathrm{CD}$ treatment does not alter ongoing or partial hepatectomy-stimulated hepatocellular regeneration.

It should be noted that liver injury measured by necrosis in 35 - and 45 -d-old rats is similar at $24 \mathrm{~h}$ in CD-treated rats (volume density of necrotic hepatocytes $=14.3 \pm 1.3 \%$ and $18.3 \pm 2.4 \%$, respectively, Fig. $6 a$ and $b$ ). This level of injury is prevented from progressing in 35-d-old rats as a result of simultaneously stimulated (3-fold) hepatocellular mitotic activity. In contrast, stimulation of mitotic activity in 45-d-old CD-treated rats was not evident (Fig. 7b). Consequently, despite a magnitude of liver injury similar to that observed in 35 -d-old rats at 24 h (Fig. $6 a$ and $b$ ), liver injury in 45-d-old rats becomes progressive at $48 \mathrm{~h}$, whereas it is completely controlled in 35-d-old rats. Similarly, among CD-pretreated rats, a comparison of the magnitude of $\mathrm{CCl}_{4}$-inflicted injury and the progression of that injury in 35-dold and 60 -d-old age groups versus the highly stimulated tissue repair in 35-d-old rats contrasted with absence of tissue repair in 60 -d-old rats is illustrative of the decisive impact of hepatocellular regeneration and tissue repair mechanisms on the ultimate outcome of toxicity initiated by $\mathrm{CCl}_{4}$.

These findings are supportive of the two-stage model of toxicity (44), wherein the early events responsible for initiating liver injury could be separated from subsequent biologic events that determine the final outcome of that injury. In the present study, a comparison of ND-fed and CD-treated rats in each age group indicates that the degree of the liver injury initiated by $\mathrm{CCl}_{4}$ (serum enzyme data, Fig. 3) is proportional to metabolic activation and tissue binding of $\mathrm{CCl}_{4}$ (Table 3). In each age group, CD treatment is associated with greater bioactivation of $\mathrm{CCl}_{4}$. However, if one compares the liver injury initiated by $\mathrm{CCl}_{4}$ and ultimate outcomes of the toxicity in various age groups, it is evident that the status of hepatocellular regeneration and tissue repair processes determine the progression or regression of the liver injury. In spite of very similar liver injury at $6 \mathrm{~h}$ when most $\mathrm{CCl}_{4}$ has been exhaled and presumably the majority of bioactivation has taken place, the ultimate outcomes are dramatically different among 35-, 45-, and 60-d-old CD-treated rats. The most readily apparent feature among these age groups is the status of ongoing and stimulated tissue repair upon initiation of injury by $\mathrm{CCl}_{4}$. The overall results suggest that the age-dependent $\mathrm{CD}$ potentiation of $\mathrm{CCl}_{4}$ toxicity is related to the balance between the $\mathrm{CCl}_{4}$-induced liver injury and the biologic responses such as hepatocellular proliferation and tissue repair leading to the recovery of liver injury rather than to the difference in the initial $\mathrm{CCl}_{4}$-induced liver injury.

The mechanisms for the unsuppressed stimulation of cellular regeneration and tissue repair by $\mathrm{CCl}_{4}$ in 35-d-old CD-treated rats are not understood at this time. Recent investigations reveal that some key factors such as TGF- $\alpha$ and TGF- $\beta$ are involved in the regulation of regenerative activity after $\mathrm{CCl}_{4}$-induced liver 


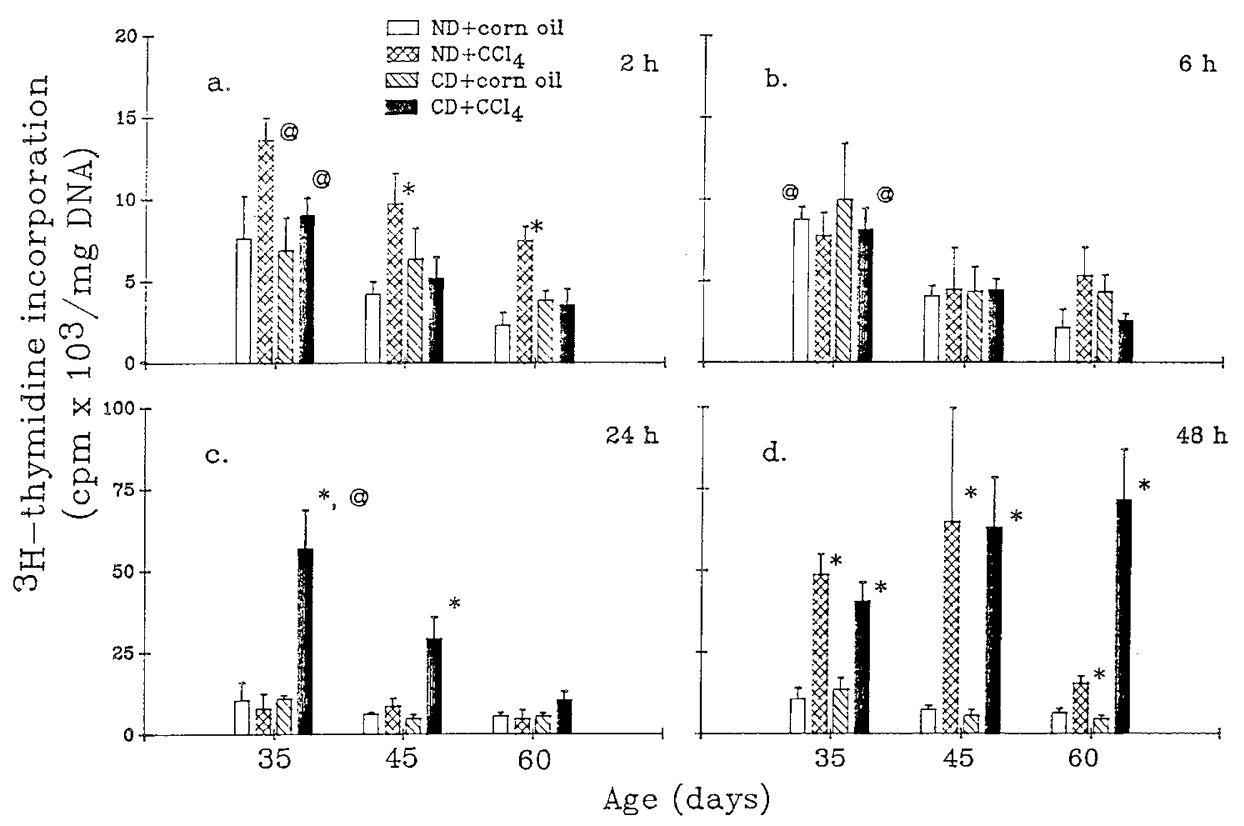

Fig. 5. ${ }^{3} \mathrm{H}-\mathrm{T}$ incorporation in the hepatic nuclear DNA at $2(a), 6(b), 24(c)$, and $48(d) \mathrm{h}$ after the injection of $\mathrm{CCl}_{4}(100 \mu \mathrm{L} / \mathrm{kg})$ or corn oil in 35-, 45-, and 60-d-old rats fed either an ND or CD diet. ${ }^{3} \mathrm{H}-\mathrm{T}$ was administered at a dose of $200 \mu \mathrm{Ci} / \mathrm{kg} 2 \mathrm{~h}$ before the animals were killed. The results represent the mean \pm SEM of at least four rats. An asterisk indicates a significantly higher value as compared with the corn oil-injected rats with the same dietary treatment. @ indicates a significantly higher value compared with that in 45- or 60-d-old rats with the same treatment.

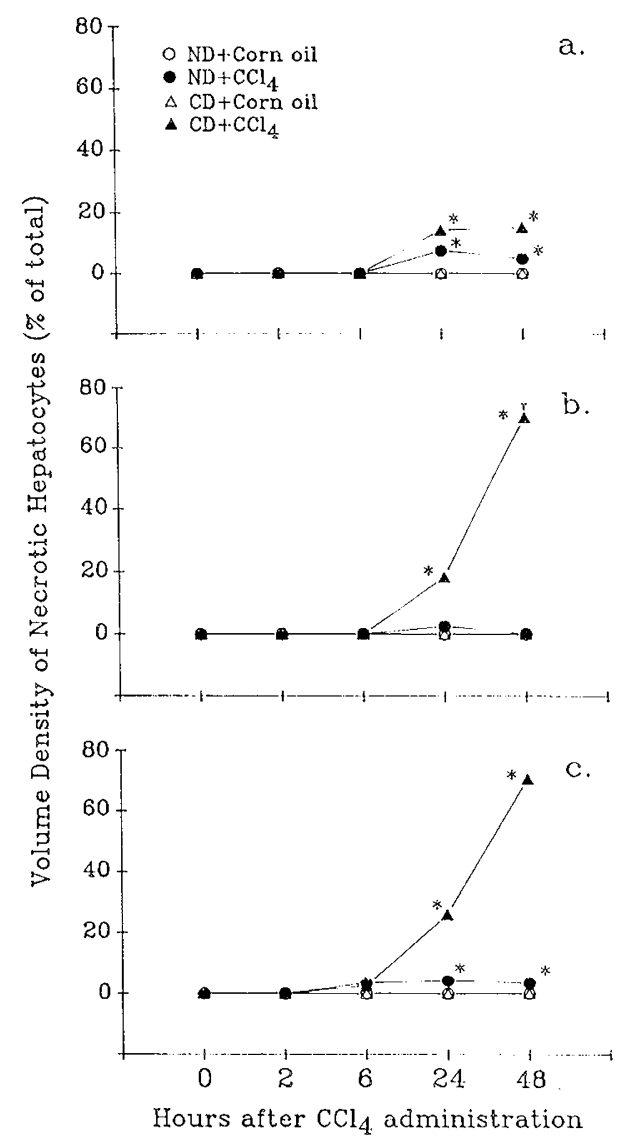

Fig. 6. Volume density of necrotic hepatocytes during a time course of $48 \mathrm{~h}$ after $\mathrm{CCl}_{4}(100 \mu \mathrm{L} / \mathrm{kg})$ or corn oil injection in $35-, 45-$, and 60 $\mathrm{d}$-old rats with or without $\mathrm{CD}$ dietary pretreatment $(a, b$, and $c$, respectively). Each point represents the mean \pm SEM of 60 to 80 randomly selected areas. An asterisk indicates a significant difference from the corn oil-injected group with the same dietary treatment at the respective time point.

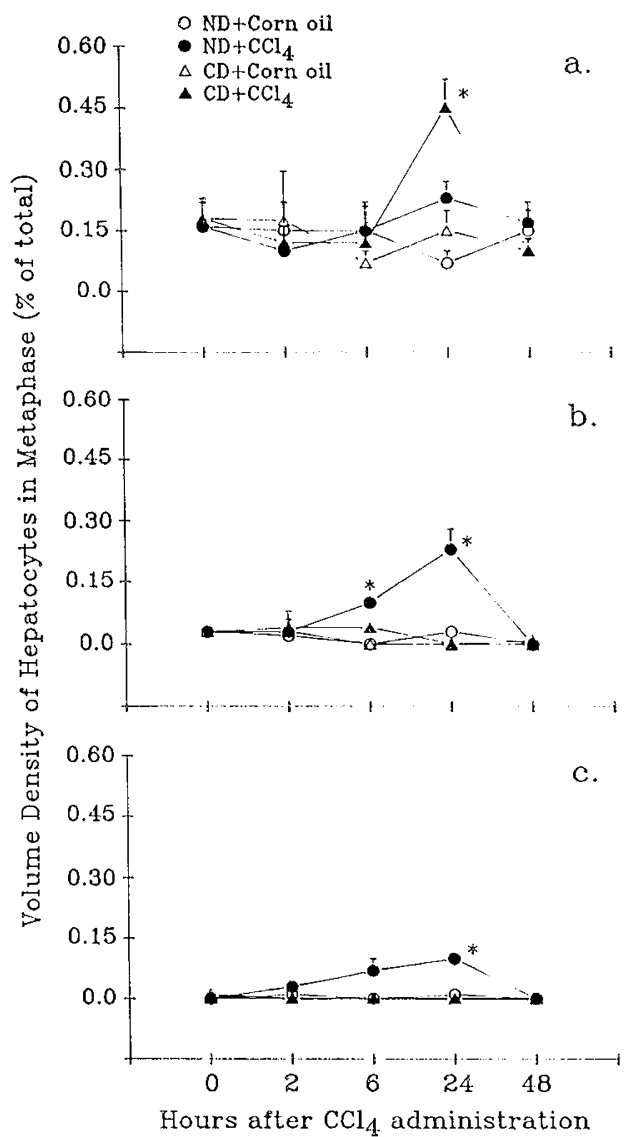

Fig. 7. Volume density of hepatocytes in metaphase during a time course of $48 \mathrm{~h}$ after $\mathrm{CCl}_{4}(100 \mu \mathrm{L} / \mathrm{kg})$ or corn oil injection in $35-, 45-$, and $60-\mathrm{d}$-old rats with or without $\mathrm{CD}$ dietary pretreatment ( $a, b$, and $c$, respectively). Each point represents the means \pm SEM of 60 to 80 randomly selected areas. An asterisk indicates a significant difference from the corn oil-injected group with the same dietary treatment at the respective time point. 
Table 3. Metabolism of ${ }^{14} \mathrm{CCl}_{4}$ in rats at various ages*

\begin{tabular}{|c|c|c|c|c|c|}
\hline \multirow[b]{2}{*}{ Age $(d)$} & \multirow[b]{2}{*}{$\operatorname{Diet} \dagger$} & \multirow{2}{*}{$\begin{array}{c}\% \text { of administered }{ }^{14} \mathrm{CCl}_{4} \\
\text { expired as free }{ }^{14} \mathrm{CCl}_{4} \ddagger\end{array}$} & \multirow{2}{*}{$\begin{array}{c}\% \text { of administered }{ }^{14} \mathrm{CCl}_{4} \\
\text { expired as }{ }^{14} \mathrm{CO}_{2}\end{array}$} & \multicolumn{2}{|c|}{ Hepatic radioactivity (dpm/g liver) } \\
\hline & & & & Total & Bound to tissue \\
\hline 35 & ND & $80.4 \pm 7.2(4)$ & $0.31 \pm 0.02$ & $766 \pm 50 \S$ & $658 \pm 38 \|$ \\
\hline 35 & $\mathrm{CD}$ & $84.0 \pm 2.1(4)$ & $0.53 \pm 0.04 \pi * *$ & $1302 \pm 190 \S$ & $1067 \pm 209 \|$ \\
\hline 45 & ND & $83.9 \pm 3.4(3)$ & $0.19 \pm 0.01$ & $1368 \pm 562 \S$ & $878 \pm 256 \|$ \\
\hline 45 & $\mathrm{CD}$ & $79.6 \pm 1.4(3)$ & $0.30 \pm 0.01 \pi$ & $2078 \pm 239$ & $1888 \pm 13$ \\
\hline 60 & ND & $84.7 \pm 2.2(3)$ & $0.16 \pm 0.03$ & $2550 \pm 189$ & $2133 \pm 174$ \\
\hline 60 & $\mathrm{CD}$ & $85.9 \pm 4.5(3)$ & $0.36 \pm 0.07 \pi$ & $3516 \pm 904$ & $3179 \pm 773$ \\
\hline
\end{tabular}

${ }^{*}$ Measurements of ${ }^{14} \mathrm{CCl}_{4}$ and ${ }^{14} \mathrm{CO}_{2}$ expiration were taken during $6 \mathrm{~h}$ at hourly intervals. The measurements of hepatic radioactivity were taken $6 \mathrm{~h}$ after the administration of ${ }^{14} \mathrm{CCl}_{4}(100 \mu \mathrm{L} / \mathrm{kg})$ in corn oil vehicle.

$+\mathrm{CD}, 10$ ppm $\mathrm{CD}$ diet.

$¥$ Numbers in parentheses are the total number of animals treated.

$\S p<0.05$ compared with 60 -d-old CD-fed rats in the same column.

$\| p<0.01$ compared with 60 -d-old CD-fed rats in the same column.

I $p<0.05$ compared with the ND group at the same age in the same column.

${ }^{* *} p<0.01$ compared with all other groups in the same column.

injury $(45,46)$. One possible explanation for lack of suppressed cell division in younger rats is that expression of endogenous mitogen TGF- $\alpha$ is more easily stimulated as a result of toxicity induced by $\mathrm{CCl}_{4}$. Another reason might be that expression of TGF- $\beta$, which regulates the level of mitotic activity stimulated by TGF- $\alpha$, might be under tighter control during early postnatal development. Whether the age-dependent resilience to $C D$ potentiation of $\mathrm{CCl}_{4}$ hepatotoxicity is associated with differences in these factors among the different age groups is a question worth further investigation.

Acknowledgment. The authors thank Dr. Evan McGee of the Mississippi Board of Animal Health Veterinary Diagnostic Laboratory, Jackson, MS, for assistance in the histopathological studies.

\section{REFERENCES}

1. Mehendale HM 1984 Potentiation of halomethane hepatotoxicity: chlordecone and carbon tetrachloride. Fundam Appl Toxicol 4:295-308

2. Klingensmith JS, Mehendale HM 1982 Potentiation of $\mathrm{CCl}_{4}$ lethality by chlordecone. Toxicol Lett 11:149-154

3. Agarwal AK, Mehendale HM 1983 Potentiation of $\mathrm{CCl}_{4}$ hepatotoxicity and lethality by chlordecone in female rats. Toxicology 26:231-242

4. Mehendale HM 1990 Potentiation of haloalkane hepatotoxicity by chlordecone: a hypothesis for the mechanism. Med Hypotheses 33:289-299

5. Charbonneau M, Ijima M, Cote MG, Plaa GL 1985 Temporal analysis of rat liver injury following potentiation of carbon tetrachloride hepatotoxicity with ketonic or ketogenic compounds. Toxicology 35:95-112

6. Glende Jr EA, Lee PY 1985 Isopropanol and chlordecone potentiation of carbon tetrachloride liver injury: retention of potentiating action in hepatocyte suspensions prepared from rats given isopropanol or chlordecone. Exp Mol Pathol 42:167-174

7. Recknagel RO, Glende Jr EA 1977 Lipid peroxidation: a specific form of cellular injury. In: Lee DHK (ed) Handbook of Physiology. Williams \& Wilkins, Baltimore, MD, pp 591-601

8. Klingensmith JS, Mehendale HM 1983 Hepatic microsomal metabolism of $\mathrm{CCl}_{4}$ after pretreatment with chlordecone, mirex, or phenobarbital in male rats. Drug Metab Dispos 11:329-334

9. Mehendale $\mathrm{HM}$, Klingensmith JS 1988 In vivo metabolism of $\mathrm{CCl}_{4}$ by rats pretreated with chlordecone, mirex, or phenobarbital. Toxicol Appl Pharmacol 93:247-256

10. Mehendale HM 1989 Amplification of hepatotoxicity and lethality of $\mathrm{CCl}_{4}$ and $\mathrm{CHCl}_{3}$ by chlordecone. Rev Biochem Toxicol 10:91-138

11. Mehendale HM 1989 Mechanism of the lethal interaction of chlordecone and $\mathrm{CCl}_{4}$ at non-toxic doses. Toxicol Lett 49:215-241

12. Lockard VG, Mehendale HM, O'Neal RM 1983 Chlordecone-induced potentiation of carbon tetrachloride hepatotoxicity: a light and electron microscopic study. Exp Mol Pathol 39:230-245

13. Lockard VG, Mehendale HM, O'Neal RM 1983 Chlordecone-induced potentiation of carbon tetrachloride hepatotoxicity: a morphometric and biochemical study. Exp Mol Pathol 39:246-255

14. Kodavanti PRS, Joshi UM, Mehendale HM 1989 Chlordecone-potentiated carbon tetrachloride hepatotoxicity in partially hepatectomized rats: a histomorphometric study. J Appl Toxicol 9:367-375

15. Kodavanti PRS, Joshi UM, Young RA, Bell AN, Mehendale HM 1989 Role of hepatocellular regeneration in chlordecone-potentiated hepatotoxicity of carbon tetrachloride. Arch Toxicol 63:367-375
16. Kodavanti PRS, Joshi UM, Young RA, Meydrech, EF, Mehendale HM 1989 Protection of hepatotoxic and lethal effects of $\mathrm{CCl}_{4}$ by partial hepatectomy. Toxicol Pathol 17:494-505

17. Young RA, Mehendale HM 1989 Metabolism and disposition of low dose of $\mathrm{CCl}_{4}$ in partially hepatectomized, chlordecone pretreated rats. $\mathbf{J}$ Biochem Toxicol 4:211-219

18. Kodavanti PRS, Kodavanti UP, Mehendale HM 1990 Altered hepatic energy status in chlordecone-potentiated $\mathrm{CCl}_{4}$ hepatotoxicity. Biochem Pharmacol 40:859-866

19. Soni MG, Mehendale HM 1991 Protection from chlordecone-amplified carbon tetrachloride toxicity by cyanidanol: biochemical and histological studies. Toxicol Appl Pharmacol 108:46-57

20. Soni MG, Mehendale HM 1991 Protection from chlordecone-amplified carbon tetrachloride toxicity by cyanidanol: regeneration studies. Toxicol Appl Pharmacol 108:58-66

21. Fouts JR, Adamson RH 1959 Drug metabolism in the newborn rabbit. Science 129:857-858

22. Klaassen CD 1972 Immaturity of the newborn rat's hepatic excretory function for ouabain. J Pharmacol Exp Ther 183:520-526

23. Klaassen CD 1973 Hepatic excretory function in the newborn rat. J Pharmacol Exp Ther 184:721-728

24. Klaassen CD 1975 Biliary excretion of drugs: role of ligandin in newborn immaturity and in the action of microsomal enzyme inducers. J Pharmacol Exp Ther 195:311-319

25. MacLeod SM, Renton KW, Eade NR 1972 Development of hepatic drugoxidizing enzymes in immature male and female rats. J Pharmacol Exp Ther 183:489-498

26. Short CR, Kinden DA, Stith R 1976 Fetal and neonatal development of the microsomal monooxygenase system. Drug Metab Rev 5:1-42

27. Slater TF 1984 Free-radical mechanisms in tissue injury. Biochem J 222:1-15

28. Sipes GI, Krishna G, Gillette JR 1977 Bioactivation of carbon tetrachloride, chloroform and bromotrichloromethane: role of cytochrome P-450. Life Sci 20:1541-1548

29. Curtis LR, Mehendale HM 1980 Specificity of chlordecone-induced potentiation of carbon tetrachloride hepatotoxicity. Drug Metab Dispos 8:23-27

30. Lowry OH, Rosebrough NJ, Farr AL, Randall RJ 1951 Protein measurement with the Folin phenol reagent. J Biol Chem 193:265-275

31. Omura T, Sato R 1964 The carbon monoxide-binding pigment of liver microsomes. 1. Evidence for its hemoprotein nature. J Biol Chem 239:2370 2378

32. Reitman S, Frankel S 1957 Colorimetric method for the determination of serum oxaloacetic and glutamic pyruvic transaminases. Am J Clin Pathol 28:53-56

33. Weibel ER, Staubli W, Gaugi HR, Hess FA 1969 Correlated morphometric and biochemical studies on the liver ccll. J Cell Biol 42:68-91

34. Curtis, LR, Mehendale HM 1981 Hepatobiliary dysfunction and inhibition of adenosine triphosphatase activity of bile canaliculi-enriched fraction following in vivo mirex, photomirex, and chlordecone exposures. Toxicol Appl Pharmacol 61:429-440

35. Cai Z, Mehendale HM 1991 Hepatotoxicity and lethality of halomethanes in Mongolian gerbils pretreated with chlordecone, phenobarbital and mirex. Arch Toxicol 65:204-212

36. Chang LO, Looney WB 1965 A biochemical and autoradiographic study of the in vivo utilization of tritiated thymidine in regenerating rat liver. Cancer Res 25:1817-1822

37. Burton K 1956 A study of the conditions and mechanism of the diphenylamine reaction for the colorimetric estimation of DNA. Biochem $\mathrm{J}$ 62:315-323

38. Cai Z, Mehendale HM 1990 Lethal effects of $\mathrm{CCl}_{4}$ and its metabolism by gerbils pretreated with chlordecone, phenobarbital and mirex. Toxicol Appl Pharmacol 104:511-520

39. Dawkins MJR 1963 Carbon tetrachloride poisoning in the liver of the newborn rats. J Pathol Bacteriol 85:189-196 
40. Cagen SZ, Klaassen CD 1979 Hepatotoxicity of carbon tetrachloride in developing rats. Toxicol Appl Pharmacol 50:347-354

41. Rikans LE 1989 Influence of aging on chemically induced hepatotoxicity: role of age-related changes in metabolism. Drug Metab Rev 20:87-110

42. Burk RF, Hill KE, Lane JM 1988 Inhibition of $\mathrm{CCl}_{4}$ metabolism by oxygen varies between isoenzymes of cytochrome P-450. Biochem Biophys Res Commun 152:1463-1467

43. Persson JO, Terelius Y, Ingelman-Sundberg M 1990 Cytochrome P-450dependent formation of reactive oxygen radicals: isozyme-specific inhibition of P-450-mediated reduction of oxygen and carbon tetrachloride. Xenobiotica 20:887-900

44. Mehendale HM 1991 Role of hepatocellular regeneration and hepatolobular healing in the final outcome of liver injury: a two-stage model of toxicity. Biochem Pharmacol 42:1155-1162

45. Armendria-Borunda J, Seyer JM, Kang AH, Raghow R 1990 Regulation of $\mathrm{TGFb}$ gene expression in rat liver intoxicated with carbon tetrachloride. FASEB J 4:215-221

46. Michalopoulos GK 1990 Liver regeneration: molecular mechanism of growth control. FASEB J 4:176-187

\section{Announcement}

In view of the appalling events that have occurred in Somalia in the past several months, there is a recognized need in Somalia for medical expertise at the most basic level of pediatric and nutritional care. Moreover, this need is likely to exist for months and even years beyond resolution of the political and social events presently taking place.

Accordingly, you are being asked to join in a volunteer effort to provide medical care to an entire generation of infants and children in Somalia. Due to the current civil unrest in that country, there is no intent to begin provision of such care until order is restored. However, to avoid undue delay at that time, we are asking now for the names of volunteers. By organizing now, it will be possible to mount a meaningful effort within days that might otherwise require months. Because there are thousands of deaths weekly in Somalia, by starting now we may be able to save many thousands of children who will undoubtedly die without us.

Because it is likely that the need for our services will extend beyond a 12-month period, volunteers for 1 to 4 months (or longer), as schedules permit, within the next 24-month period will be gratefully accepted.

For more information, please contact: Karl S. Roth, M.D., or Festus O. Adebonojo, M.D., Department of Pediatrics, Medical College of Virginia, Childrens Medical Center, Box 239, Richmond, VA 23298-0239. 